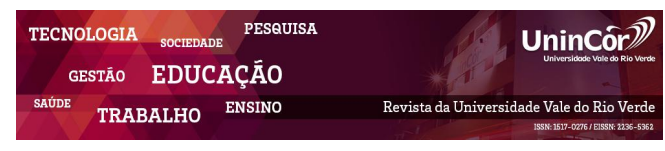

Revista da Universidade Vale do Rio Verde ISSN: 1517-0276 / EISSN: 2236-5362 v. 16 | n. 1 | Ano 2018

Hellen Catarinne Pereira dos Santos de Santana

Faculdade Maria Milza - FAMAM hellencatarinne@gmail.com

Fernando Francisco Chagas dos Santos Faculdade Maria Milza - FAMAM ffchagas@live.com

Ana Conceição de Oliveira Cravo Teixeira Faculdade Maria Milza - FAMAM aninhacravo@yahoo.com.br

Larissa Rolim Borges-Paluch Faculdade Maria Milza - FAMAM larissapaluch@gmail.com

\section{CÁRIE DENTÁRIA: FATORES DE RISCO EM ESCOLARES DO ENSINO PÚBLICO FUNDAMENTAL}

\section{RESUMO}

O objetivo foi avaliar a influência de fatores associados com a presença de cárie em escolares do ensino fundamental de um município do Recôncavo Baiano. A coleta dos dados aconteceu no município de Governador Mangabeira, BA, sendo enviado aos pais/responsáveis questionário com perguntas referentes aos fatores sociodemográficos e econômicos; comportamentais/hábitos, e uso dos serviços odontológico. Posteriormente foi realizada a avaliação da cavidade bucal dos estudantes selecionados, seguindo os critérios padronizados pela Organização Mundial da Saúde. Foi realizada a mensuração da experiência de cárie dentária pelos índices de dentes cariados, perdidos ou obturados (CPO-D e CEO-d). Dos 252 escolares participantes do estudo $130(51,6 \%)$ possuíam cárie, e dentre estes pode se observar relação estatística significativa com o fator étnico racial cor/raça melanoderma e baixa escolaridade dos pais com a ocorrência de cárie. Os demais fatores não tiveram associações estatísticas, sendo um provável resultado da organização e gestão da saúde do município. Conclui-se que houve relação da ocorrência de cárie com um fator demográfico e um socioeconômico sendo necessária a priorização de medidas educativas em saúde bucal na população estudada, principalmente, em relação a esses fatores.

Palavras-chave: Cárie Dental. Epidemiologia. Saúde Bucal.

\section{DENTAL CARIES: RISK FACTORS IN STUDENTS OF ELEMENTARY PUBLIC SCHOOLS}


system organization and management in the municipality. Notwithstanding, it is necessary to implement educational measures for the population under study to reduce the association between caries and social, demographic and economic factors.

Keywords: Dental Caries. Epidemiology. Oral Health.

\section{INTRODUÇÃO}

A Organização Mundial de Saúde (OMS) define saúde como um estado de bemestar físico, psíquico e social (SEGRE; FERRAZ, 1997). A mesma definição pode se aplicar à saúde bucal, que deve ser vista de maneira ampla, deixando de ser avaliada única e exclusivamente tecnicamente. A promoção em saúde bucal deve acontecer juntamente com outras atividades de saúde coletiva, e para que isso ocorra, é preciso que a população desenvolva um pensamento sanitário, segundo o qual os pilares do SUS (integralidade, universalidade e equidade) sejam percebidos como um direito conquistado para permitir a participação no processo de controle social dos seus serviços e ações (BRASIL, 2004).

Ainda de acordo com os autores acima, as Diretrizes da Política Nacional de Saúde Bucal do Ministério da Saúde visam conhecer a realidade de saúde de cada local, adequando suas ações e serviços às necessidades da população. Além disso, é preciso estabelecer um estreito relacionamento com as pessoas para conhecer o seu estilo e condições de vida, sua religião e hábitos e a concepção que possuem de sua saúde e as ações que realizam para prevenir e curar doenças.

Portanto, realizar levantamentos epidemiológicos periodicamente gera um grande impacto positivo quando se trata dos cuidados nos níveis individuais e coletivos, onde todos se tornam corresponsáveis pela saúde bucal. Além disso, esses levantamentos possibilitam o planejamento, avaliação e monitoramento adequado das condições bucais da população estudada, o que acaba por tornarse uma das soluções de tais problemas (MÜLLER et al., 2015).

Levantamentos epidemiológicos foram realizados em território brasileiro nos anos de 1986, 1996, 2003 e 2010 pelo Ministério da Saúde. Esses levantamentos serviram de base para a construção epidemiológica de saúde bucal da população nacional, pois a partir dos dados coletados foi possível, em 2004, implementar a Política Nacional de Saúde Bucal (Brasil Sorridente), que integralizou a Odontologia. Nesta, foram incorporados procedimentos mais complexos no âmbito da atenção básica e a criação de centros de especialidades odontológicas (BRASIL, 2011).

Estes trabalhos, além de estudarem a população em relação à cárie dentária, exploram níveis sociais, culturais, econômicos, de gênero, etnia e faixa etária dos indivíduos permitindo uma implementação de ações em conformidade com a necessidade de cada um (CARVALHO, 2009).

Apesar do declínio do número de caries desde o último levantamento de saúde bucal, em 2003, ainda há desigualdade nos 
índices de cárie nas diferentes regiões do Brasil. Cor/raça, situação socioeconômica, higiene bucal e água fluoretada, foram fatores determinantes para essa redução (FREIRE et al., 2013).

A odontologia brasileira, embora seja avaliada como uma das mais avançadas do mundo, deixa grande parte da população à margem de uma boa assistência que previna, diagnostique e cure problemas recorrentes em se tratando de doenças bucais como as cáries e as doenças periodontais. E quanto menor a escolaridade e acesso à informação da população, menor é a procura por serviço (público ou privado) odontológico, tornando difícil a promoção e educação em saúde bucal (PORTO; PEREIRA; NETTO, 2008).

A cárie dentária é uma doença que possui uma grande prevalência e por isso consegue ser analisada de maneira multidisciplinar. Esta pode ser classificada bioquimicamente, bacteriologicamente, histologicamente, clinicamente, politicamente e também epidemiologicamente. Existem muitas variáveis que influenciam nos padrões da cárie, dentre elas se destacam: a fluoretação do creme dental e da água de abastecimento, melhoria da qualidade de vida, municipalização da saúde, ações preventivas/educativas e implantação do Sistema Único de Saúde (SUS) (FRIAS; FRATUCCI, 2008).

Nesse contexto, o objetivo do presente trabalho foi relacionar fatores sociodemográficos e econômicos; comportamentais/hábitos, e uso dos serviços odontológicos com a ocorrência da cárie em escolares do ensino fundamental de um município do Recôncavo da Bahia.

$\mathrm{O}$ estudo justifica-se pelo fato da doença cárie ser altamente prevalente no país e estar diretamente relacionada a fatores biológicos, socioeconômicos $\mathrm{e}$ comportamentais. E, portanto é imprescindível gerar medidas coletivas de prevenção e promoção visando a redução desse agravo. Os resultados do estudo podem ser utilizados por gestores em saúde pública a fim de conhecer a realidade do município e planejar ações objetivando maior resolutividade desse problema bucal.

\section{METODOLOGIA}

A pesquisa contemplou um estudo de natureza descritiva com abordagem quantitativa sendo realizada em escolas municipais de Governador Mangabeira, localizado no Recôncavo da Bahia.

O município ocupa uma área de $106.317 \mathrm{~km}^{2}$ e possui aproximadamente 19.818 habitantes, o que representa uma densidade demográfica de 186.40 habitantes $\mathrm{km}^{2}$ (BRASIL, 2013). De acordo com dados do último censo do Instituto Brasileiro de Geografia e Estatística (IBGE), há no município 21 escolas pré-escolares e 26 escolas de ensino público municipal em nível fundamental, totalizando 4.287 alunos matriculados (BRASIL, 2015). 
Foram utilizados como critérios de inclusão para as escolas: possuir estudantes matriculados na faixa etária de 6 a 12 anos, disponibilidade para a realização da pesquisa durante o período da coleta de dados e estar coberta por Postos de Saúde com serviço odontológico. E como critérios de exclusão: ter menos de 20 discentes matriculados na faixa etária determinada.

\section{Participantes do Estudo}

A população estudada abrangeu discentes de escolas municipais no referido município. Os critérios de inclusão foram idade entre 6 e 12 anos, estar devidamente matriculado e os pais/responsáveis aceitarem participar do estudo. O critério de exclusão foi não estar presente na escola durante o período da coleta dos dados.

Procedimentos e Instrumentos de Coleta

Após a autorização da direção das escolas para a realização do trabalho de campo, foi enviado um comunicado sobre a pesquisa aos pais/responsáveis explicando o seu objetivo e relevância juntamente com o Termo de Consentimento Livre e Esclarecido, para ser assinado em duas vias. Nessa oportunidade também foi solicitado o preenchimento de um questionário composto por perguntas objetivas para obtenção de dados referentes as variáveis sociodemográficas do escolar (gênero, idade, cor/raça $\left.{ }^{1}\right)$; variáveis sociodemográfica dos

\footnotetext{
${ }^{1}$ A nomenclatura adotada para a identificação da raça/cor da pele na área médico-legal foi introduzida por
}

pais/responsáveis (renda mensal, idade, estado civil e escolaridade) e localização geográfica da escola; comportamento/hábito do escolar (número diário de escovações, quem realiza a limpeza, ingestão de verduras e frutas, ingestão de gorduras e frituras, ingestão de bebidas cariogênicas/adoçadas); e uso dos serviços odontológicos pelo escolar (frequência de consulta odontológica e experiência de cárie).

As datas e horário para a coleta de dados foram previamente agendados nas escolas selecionadas. Aos discentes que preencherem os critérios de inclusão foi solicitada assinatura no Termo de Assentimento Livre e Esclarecido.

Posteriormente, uma equipe composta de um examinador devidamente calibrado e treinado (graduando de Odontologia) e pelo odontopediatra (docente) que exerceu a função de anotador e supervisor, realizou os exames clínicos.

Para o processo de calibração, os critérios de diagnóstico para exames em dentes decíduos foram amplamente estudados e discutidos, utilizando como referencia o Manual de Instruções para Levantamento Epidemiológico Básico de Saúde Bucal da Organização Mundial de Saúde (OMS). Na aferição do erro intraexaminador foi adotado o Coeficiente de Kappa, obtendo-se nível de

Roquette-Pinto (1933), levando-se em conta, sobretudo, a cor da pele e cujas denominações foram adaptadas do grego: melanoderma (melanodermos) para pretos; leucoderma (leucodermos) para brancos; faioderma (phaiodermos) para pardos; xantoderma (xanthodermos) para amarelo e eritroderma para indígenas (Ramos, 2003). 
concordância intra e inter-examinadores acima de 0,70 . Ao final de 30 dias, foi reexaminada $5 \%$ da amostra, escolhida aleatoriamente, para avaliar a manutenção da concordância intra e inter-examinadores.

As normas de biossegurança foram criteriosamente respeitadas durante os exames clínicos, sendo utilizados Equipamentos de Proteção Individual (EPI) em todas as coletas.

Durante a realização do exame os estudantes ficaram sentados com a cabeça inclinada ou deitados sobre uma mesa, em decúbito dorsal. $\mathrm{O}$ examinador ficou posicionado de maneira a proporcionar uma melhor visualização, estando o anotador ao seu lado. O exame foi realizado o mais próximo possível das janelas, para que houvesse um melhor aproveitamento da luz natural. Quando houve problema de luminosidade, foi utilizada luz artificial (lanterna de mão). O método para o diagnóstico de lesão de cárie foi visual com auxílio de abaixadores de língua descartáveis para afastar lábios e língua.

Para a mensuração da experiência de cárie dentária se avaliou os índices de dentes permanentes cariados, perdidos ou obturados (CPO-D) de acordo com os critérios de diagnóstico da OMS (1997).

Análise de Dados

A amostragem realizada foi probabilística do tipo aleatória estratificada. $\mathrm{O}$ tamanho da amostra foi calculado pelo programa Statdisk 12.0.2, visando estimar parâmetros populacionais com prevalência de
0,5; intervalo de $95 \%$ de confiança; e um nível de precisão $(\mathrm{p}<0,05)$, o que evidenciou a necessidade de se avaliar um mínimo de 250 discentes. Para o processamento dos dados coletados foi utilizado o Microsoft Office Excel, e a análise estatística foi realizada utilizando-se os softwares BioEstat 5.3 e SPSS versão 22.0.

Para a análise dos fatores associados à presença de cárie utilizou-se o modelo de regressão logística múltipla não condicional. De forma preliminar, para a seleção das variáveis mais representativas, utilizou-se a análise por regressão logística binomial como procedimento para a inclusão das variáveis, considerando-se as razões de chances (odds ratio) brutas e ajustadas, com seus respectivos intervalos a 95\% de confiança. Nesta análise, o critério de inclusão das variáveis explicativas no modelo foi apresentar um nível de significância descritivo $(\mathrm{p}<0,20)$ na análise bivariada. Desta forma, realizou-se um teste bivariado preliminar com o valor probabilidade (p-valor) a $20 \%$ e, em seguida, fez-se uma nova avaliação múltipla, agora com todas as variáveis independentes pré-selecionadas, utilizando o critério de significância $(\mathrm{p}<0,05)$. Para avaliar o grau de acurácia do modelo logístico obtido, utilizou-se o Teste de Hosmer e Lemeshow.

O presente estudo possui aprovação do Comitê de Ética em Pesquisa da Faculdade Maria Milza, parecer consubstanciado 1.306.320, e respeitou às normas éticas em pesquisa com seres humanos conforme 
Resolução 466/12 do Conselho Nacional de Saúde.

\section{RESULTADOS E DISCUSSÃO}

Dados Demográficos dos Escolares

Depois de aplicados os critérios, a municipais, sendo quatro localizadas na zona urbana e quatro na rural., totalizando 252 estudantes, predominantemente do gênero feminino $(51,6 \%)$, cor/raça faioderma $(58,3 \%)$ e idade de dez anos $(30,6)$ (Tabela 1).

amostra foi constituída por oito escolas

Tabela 1. Perfil demográfico de escolares do ensino fundamental municipal de Governador Mangabeira, BA, 2017.

\begin{tabular}{lcc|lcr}
\hline VARIÁVEL & $\mathrm{N}$ & $\%$ & VARIÁVEL & $\mathrm{N}$ & $\%$ \\
\hline GÊNERO & & & IDADE (ANOS) & & \\
Masculino & 122 & 48,4 & 06 anos & 06 & 02,3 \\
Feminino & 130 & 51,6 & 07 anos & 19 & 07,5 \\
COR/RAÇA & & & 08 anos & 37 & 14,7 \\
Leucoderma & 18 & 07,1 & 09 anos & 75 & 29,7 \\
Melanoderma & 87 & 34,5 & 10 anos & 80 & 31,7 \\
Faioderma & 147 & 58,3 & 11 anos & 27 & 10,7 \\
& & & 12 anos & 08 & 03,1 \\
\hline
\end{tabular}

Fonte: Dados da pesquisa, 2017.

Presença de Cárie

Foi observado que dos 252 escolares amostrados, $130(51,58 \%)$ possuem cárie; entretanto, esse número soube para 176 $(69,84 \%)$ quando se incluem os estudantes que já tiveram experiência anterior de cárie.

Nos estudos de Silveira et al. (2015), em adolescentes residentes do norte de Minas Gerais, foram avaliados fatores associados à cárie dentaria e encontrados um índice de $71,3 \%$ entre indivíduos com cárie e experiências cumulativas da doença, valor muito semelhante à pesquisa em questão.
Correlação da cárie com dados demográficos Gênero

Não foram encontradas associações do gênero do escolar com a presença de cárie neste estudo, sendo que dos 252 discentes avaliados $130(51,6 \%)$ possuíam cárie e pouco mais da metade $(51,53 \%)$ pertencem ao gênero masculino (Tabela 2). 
Tabela 2. Análise da associação entre a presença de cárie e características sociodemográfica e econômica, comportamento/hábitos e uso dos serviços odontológicos. Governador Mangabeira, BA, 2017.

\begin{tabular}{|c|c|c|c|c|c|}
\hline VARIÁVEIS & $\begin{array}{c}\text { Com Cárie } \\
\text { N (\%) }\end{array}$ & $\begin{array}{c}\text { Sem Cárie } \\
\text { N (\%) }\end{array}$ & OR & IC 95\% & $\begin{array}{c}\text { Valor de } \\
\text { p }\end{array}$ \\
\hline \multicolumn{6}{|c|}{ SOCIODEMOGRÁFICA E ECONÔMICA } \\
\hline \multicolumn{6}{|l|}{ GÊNERO } \\
\hline Masculino & $67(51,53)$ & $55(45,10)$ & 1 & & \\
\hline Feminino & $63(48,46)$ & $67(54,90)$ & 1,388 & $0,768-2,508$ & 0,278 \\
\hline \multicolumn{6}{|l|}{ COR/RAÇA } \\
\hline Leucoderma & $08(06,60)$ & $10(07,80)$ & 1 & & \\
\hline Melanoderma & $52(40,00)$ & $35(28,60)$ & 1,684 & $0,533-5,319$ & 0,059 \\
\hline Faioderma & $70(53,40)$ & $77(63,60)$ & 1,015 & $0,329-3,126$ & 0,980 \\
\hline \multicolumn{3}{|c|}{ IDADE DO ESCOLAR (ANOS) } & 1,094 & $0,865-0,865$ & 0,455 \\
\hline \multicolumn{6}{|c|}{ ESCOLARIDADE DOS PAIS/RESPONSÁVEL } \\
\hline Analfabeto & $10(07,60)$ & $03(02,40)$ & 1 & & \\
\hline Primário & $28(21,50)$ & $30(24,60)$ & 0,302 & $0,062-1,467$ & 0,138 \\
\hline Ginásio & $26(20,00)$ & $25(20,50)$ & 0,211 & $0,041-1,084$ & 0,062 \\
\hline Ensino Médio & $53(40,70)$ & $55(45,00)$ & 0,219 & $0,046-1,041$ & $\mathbf{0 , 0 5 6}$ \\
\hline Superior & $13(10,20)$ & $03(07,50)$ & 0,260 & $0,042-1,616$ & 0,148 \\
\hline \multicolumn{6}{|c|}{ RENDA FAMILIAR (SALÁRIO MÍNIMO) } \\
\hline Até 1 Salário & $109(83,80)$ & $93(76,20)$ & 1 & & \\
\hline 1 salário & $15(11,50)$ & $21(17,20)$ & 1,088 & $0,424-2,796$ & 0,860 \\
\hline Entre 1 e 2 & $06(04,70)$ & $08(06,60)$ & 0,922 & $0,226-3,753$ & 0,909 \\
\hline \multicolumn{6}{|c|}{ IDADE DOS PAIS/RESPONSÁVEL } \\
\hline 19 a 29 anos & $29(22,3)$ & $18(14,70)$ & 1 & & \\
\hline 30 a 49 anos & $93(71,5)$ & $97(79,50)$ & 0,598 & $0,262-1,367$ & 0,223 \\
\hline Mais de 49 & $08(06,20)$ & $07(05,80)$ & 0,530 & $0,106-2,641$ & 0,439 \\
\hline \multicolumn{6}{|c|}{ ESTADO CIVIL DOS PAIS/RESPONSÁVEL } \\
\hline Solteiro & $29(22,30)$ & $18(14,7)$ & 1 & & \\
\hline Casado & $80(61,50)$ & $97(79,5)$ & 1,123 & $0,523-2,414$ & 0,766 \\
\hline Separado & $21(16,20)$ & $07(05,8)$ & 2,036 & $0,723-5,737$ & 0,178 \\
\hline \multicolumn{6}{|c|}{ LOCALIZAÇÃO GEOGRÁFICA DA ESCOLA } \\
\hline Urbana & $52(40,00)$ & $66(54,00)$ & 1 & & \\
\hline Rural & $78(60,00)$ & $56(46,00)$ & 0,596 & $0,301-1,180$ & 0,138 \\
\hline
\end{tabular}




\begin{tabular}{|c|c|c|c|c|c|}
\hline \multicolumn{6}{|c|}{ NÚMERO DE ESCOVAÇÃO (DIÁRIA) } \\
\hline $1 \mathrm{x}$ ao dia & $21(16,10)$ & $20(16,40)$ & 1 & & \\
\hline $2 \mathrm{x}$ ao dia & $62(47,60)$ & $46(37,70)$ & 1,574 & $0,682-3,635$ & 0,288 \\
\hline $3 \mathrm{x}$ ao dia & $47(36,30)$ & $56(45,90)$ & 0,907 & $0,365-2,258$ & 0,834 \\
\hline \multicolumn{6}{|c|}{ INGESTÃO DE VERDURAS E FRUTAS (SEMANAL) } \\
\hline $1 \mathrm{vez}$ & $48(36,90)$ & $44(36,00)$ & 1 & & \\
\hline 2 a 3 vezes & $49(37,60)$ & $34(28,00)$ & 1,736 & $0,848-3,554$ & 0,131 \\
\hline+ de 4 vezes & $33(25,30)$ & $44(36,00)$ & 0,895 & $0,410-1,953$ & 0,781 \\
\hline \multicolumn{6}{|c|}{ INGESTÃO DE GORDURAS E FRITURAS (SEMANAL) } \\
\hline $1 \mathrm{vez}$ & $77(59,20)$ & $79(64,75)$ & 1 & & \\
\hline 2 a 3 vezes & $36(27,60)$ & $31(25,40)$ & 1,658 & $0,612-4,495$ & 0,419 \\
\hline+ de 4 vezes & $17(13,00)$ & $12(09,85)$ & 0,864 & $0,280-2,663$ & 0,320 \\
\hline \multicolumn{6}{|c|}{ INGESTÃO DIÁRIA BEBIDA CARIOGÊNICA (ADOÇADA) } \\
\hline $1 \mathrm{vez}$ & $62(47,60)$ & $63(51,60)$ & 1 & & \\
\hline 2 a 3 vezes & $20(15,30)$ & $19(15,60)$ & 0,871 & $0,379-2,004$ & 0,746 \\
\hline+ de 4 vezes & $14(10,70)$ & $12(09,90)$ & 1,390 & $0,503-3,838$ & 0,526 \\
\hline Raramente & $34(26,10)$ & $28(22,90)$ & 1,345 & $0,660-2,743$ & 0,414 \\
\hline \multicolumn{6}{|c|}{ QUEM REALIZA LIMPEZA } \\
\hline Pai/Mãe & $60(46,10)$ & $63(51,60)$ & 1 & & \\
\hline Escolar & $70(53,90)$ & $59(48,40)$ & 0,933 & $0,510-1,705$ & 0,821 \\
\hline \multicolumn{6}{|c|}{ FREQUÊNCIA DE CONSULTA ODONTOLÓGICA } \\
\hline Nunca & $23(19,80)$ & $20(16,46)$ & 1 & & \\
\hline $6 \mathrm{~m}$ a 1 ano & $64(47,20)$ & $58(47,54)$ & 2,024 & $0,572-7,168$ & 0,274 \\
\hline mais de 1 ano & $43(33,00)$ & $44(36,00)$ & 1,468 & $0,408-5,278$ & 0,556 \\
\hline \multicolumn{6}{|c|}{ EXPERIÊNCIA DE CÁRIE } \\
\hline Nunca teve & $39(30,00)$ & $39(32,00)$ & 1 & & \\
\hline Tem ou teve & $91(70,00)$ & $83(68,00)$ & 1,239 & $0,437-3,510$ & 0,687 \\
\hline
\end{tabular}

Fonte: Dados da pesquisa, 2017.

Não houve associação entre cárie e gênero neste estudo. Corroborando essa informaçao, diversos autores, ao relacionarem essas variáveis também não encontraram diferença significativa entre os gêneros
(BONOTTO et al., 2015; FREITAS; LACERDA; NEUMANN, 2013).

Entretanto, Gomes et al. (2017) observaram significativa diferença estatística de 1,17 no gênero feminino, em comparação a 0,50 no gênero masculino, ao avaliarem índice 
de cárie dental em adolescentes na cidade de Recife, PE.

Em contraponto, Farghaly et al. (2013) notaram que há uma redução do fluxo salivar nas crianças que possuíam cárie, sendo essa redução maior no gênero feminino, tornando-as mais suscetíveis à cárie e outras doenças de origem microbiana na cavidade oral.
Idade

Também não foram encontradas relações entre a idade e a presença de cárie nos estudantes avaliados (Tabela 2). A maioria dos escolares com cárie estava na faixa etária de 09 a 10 anos, somando 59,4\% do total (Tabela 3).

Tabela 3. Presença de cárie associada à idade em escolares de Governador Mangabeira, BA.

\begin{tabular}{llclc}
\hline IDADE & \multicolumn{2}{l}{ COM CÁRIE } & \multicolumn{2}{l}{ SEM CÁRIE } \\
\hline & $\mathrm{N}$ & $\%$ & $\mathrm{~N}$ & $\%$ \\
$\mathbf{0 6}$ & 03 & 2,3 & 03 & 2,4 \\
$\mathbf{0 7}$ & 10 & 7,6 & 09 & 7,3 \\
$\mathbf{0 8}$ & 20 & 15,3 & 17 & 13,9 \\
$\mathbf{0 9}$ & 42 & 31,2 & 33 & 27 \\
$\mathbf{1 0}$ & 37 & 28,2 & 43 & 35,2 \\
$\mathbf{1 1}$ & 11 & 8,4 & 16 & 12,2 \\
$\mathbf{1 2}$ & 07 & 7,0 & 01 & 2,0 \\
\hline
\end{tabular}

Fonte: Dados da pesquisa, 2017.

Almeida et al. (2012), ao observarem o índice CPO-D de crianças de 12 anos, adolescentes entre 15 e 19 anos e adultos de 35 a 44 anos, perceberam que o índice de cárie nestes indivíduos era inversamente proporcional a faixa etária, sendo $\quad 60,7 \%, \quad 54,0 \%$ e $\quad 19,0 \%$, respectivamente.

Essa informação também é corroborada pelo estudo realizado pelo Ministério da Saúde em todas as 26 capitais brasileiras, Distrito Federal e mais cinco cidades do interior (uma por região). O índice CPO-D encontrado em 2010 foi de 2,43 em crianças de 5 anos de idade, totalizando $80 \%$ de unidades dentárias cariadas. Em crianças de 12 anos o índice ficou em 2,07, indicando que o índice de cárie diminuiu de acordo com o aumento da idade dos indivíduos avaliados (BRASIL, 2010).

Esse fato pode estar associado à percepção de autocuidado que os indivíduos desenvolvem ao longo da vida, favorecendo não apenas a preocupado com a aparência, para atender padrões impostos pela sociedade, mas também para melhorar o bem estar pessoal e a qualidade de vida. 
Contrariamente, Carvalho (2009) relata que na faixa entre 03 e 06 anos, o índice de cariados aumenta conforme a idade, partindo de 1,13 para 1,68 aos 6 anos. $O$ fato pode estar relacionado ao aumento do número de unidades dentárias até a finalização da erupção de todos os dentes permanentes.

\section{Cor/Raça}

Foi possível observar correlação estatística da característica étnico-racial com a presença de cárie. Dos 87 estudantes de cor/raça melanoderma envolvidos na pesquisa, 52 possuíam cárie, ou seja, 59,7\% (Tabela 2).

Silveira et al. (2015) também encontraram associação da cor/raça e a ocorrência de cárie, pois dos 763 jovens que participaram do estudo em Montes Claros (MG), 542 (71\%) possuíam cárie. Dentre os indivíduos com dentes cariados, 218 (40,3\%) se autodeclararam melanoderma, faioderma ou eritroderma.

Ao estudarem a comunidade do Dendê, no Ceará, Moreira, Nations e Alves (2007) constataram que esta população visualiza a doença cárie não apenas como uma consequência física, mas principalmente social em função do acesso desigual aos serviços de saúde e exclusão social. Segundo Guiotoku et al. (2012) esta associação advém de um contexto histórico de iniquidade social, pois a população meloderma sofre maior discriminação social em relação à parda e indígena no que se refere à distribuição de renda e atenção à saúde, acarretando maior vulnerabilidade aos agravos que comprometem a saúde bucal deste grupo.

Relação dos Fatores Socioeconômicos com a Ocorrência de Cárie na Cavidade Bucal Influência dos pais

No presente estudo, foi encontrada uma relação estatisticamente significativa entre a escolaridade dos pais/responsáveis e a ocorrência de cárie nos escolares, sendo que os pais com ensino médio possuem mais filhos com cárie (tabela 2).

Nossos resultados divergem dos de Freitas, Lacerda e Neumann (2013) e Figueira e Leite, (2008). Nesses estudos, pais analfabetos ou com ensino fundamental geralmente possuiam mais filhos com cárie. Um provável motivo seria o cotidiano, onde os responsáveis geralmente passam grande parte do dia trabalhando, sobrando pouco tempo para se dedicar à saúde bucal dos filhos.

Para Souza (2015), em estudo realizado com escolares da zona rural de um município de Minas Gerais, a escolaridade dos pais, principalmente a da mãe (fundamental incompleto) e a renda inferior a dois salários mínimos estão entre os fatores que determinam a redução desigual da doença cárie no Brasil.

Borges et al. (2015), constataram que crianças que possuíam mães que estudaram até o quarto ano do ensino fundamental, tinham duas vezes mais chances de adquirir a cárie em relação às crianças com mães com maior escolaridade. Entretanto, os indivíduos com mães que concluíram o segundo grau, tinham 
81\% mais de chances de desenvolver cárie dentária se comparados às crianças cujas mães possuíam o terceiro grau completo.

Porém, Santos et al. (2017), em estudo realizado em Governador Mangabeira (BA), com estudantes de escolas públicas e privadas, não encontraram diferença estatística no que concerne à prevalência de cárie e escolaridade dos pais. A amostra foi constituída por 285 pais/responsáveis, dos quais 124 (43,5\%) possuíam ensino médio.

Entretanto, Almeida et al. (2011), ao pesquisarem a relação de cárie de mães e seus filhos de 3 a 12 anos, em uma clínica escola da cidade de Recife (PE), verificaram um índice CPO-D alto tanto nas mães quanto nas crianças, 11,7 e 5,92, respectivamente. Os autores observaram que além da baixa escolaridade das progenitoras, a renda familiar foi igual ou inferior a um salário mínimo, confirmando nesse estudo o vínculo entre cárie e fator socioeconômico e verificando também a grande influência da mãe na saúde bucal do filho.

Cypriano et al. (2011), ao estudarem 266 discentes de 12 anos de escolas públicas e/ou particulares da cidade de Jundiaí (SP), verificaram que $53 \%$ dos estudantes amostrados possuíam cárie, sendo o índice CPO-D dos meninos 1,5 e das meninas 1,9. A baixa escolaridade do responsável influenciou no índice de cárie destes escolares, sendo observado que $59 \%$ dos pais/responsáveis possuíam menos de oito anos de estudo.
Local de estudo

Apesar de não haver diferenças estatisticamente significativas, pode-se observar relação entre o local do estudo e ocorrência de cárie nos escolares, pois $60 \%$ dos que possuíam a doença estudavam na zona rural (Tabela 2). Esse fator pode estar relacionado à dificuldade de acesso a saúde, já que nessas áreas a oferta de serviços de saúde é menor.

Santos et al. (2017), em um estudo com escolares de 08 a 12 anos de instituições públicas e particulares, urbanas e rurais, no mesmo município baiano da presente pesquisa (Governador Mangabeira), também não encontraram relações estatísticas com a cárie e o fator localização da escola. Todavia, o índice CPO-D dos discentes da zona urbana foi menor $(1,38)$ quando comparado ao da zona rural $(2,21)$.

Apesar de não ter encontrado correlação estatística, Freitas, Lacerda e Neumann (2013), ao avaliarem escolares de sete anos da cidade de Joinville (SC), afirmam que os estudantes de escolas públicas situadas em regiões de baixa renda apresentavam maior experiência de cárie, encontrando um índice CPO-D de 2,50 em relação às escolas situadas em regiões de renda superior $(1,24)$. Uma das causas discutidas foi a dificuldade de acesso aos serviços odontológicos.

Souza et al. (2015), em um estudo com discentes de 4 a 22 anos da zona rural do estado de Minas Gerais, encontraram um CPO- 
D de 4,31 em crianças de 12 anos. Esse índice é considerado alto quando comparado com o nacional, pois de acordo com um estudo nacional realizado 2010, crianças dessa idade apresentaram uma média de 2,07 (BRASIL, 2011).

Um ponto que deve ser destacado é que até novembro de 2016 a água não era fluoretada na zona rural de Governador Mangabeira, sendo oriunda de fossas sépticas, cisternas e poços artesianos. A partir dessa data, treze comunidades da zona rural foram beneficiadas com o abastecimento hídrico potável (SANTOS et al., 2017).

Relação dos Fatores Comportamentais/Hábitos com a Ocorrência de Cárie na Cavidade Bucal Alimentação

Não houve diferença estatística entre o tipo de alimento consumido pelos escolares e a presença de cárie (Tabela 2). Entretanto, é notório o conhecimento de que a alimentação influencia diretamente na progressão da doença cárie. Portanto, é dever do profissional em saúde bucal informar e orientar os pacientes de forma clara e compreensível sobre a importância de uma boa alimentação para prevenção da cárie dentária.

De acordo com estudos de Silva et al. (2015), a alimentação está intimamente ligada a hábitos sociais, econômicos e culturais. E crianças e adolescentes escolhem as suas práticas alimentares guiados pela opinião de amigos, pelo ambiente familiar e principalmente pela mídia, que através de seus comerciais impõe estereótipos definidos pelo interesse comercial mais do que pela saúde.

Segundo Müller et al. (2015), crianças com cárie ativa aos cinco anos de idade relataram possuir dor na mastigação. Por conseguinte, cárie não tratada pode ter severa repercussão na qualidade alimentar do indivíduo.

Crianças e adolescentes com preferência por alimentos com alto teor de gorduras, açúcares e sódio são não só mais propensos ao surgimento da cárie, mas também estão sujeitos ao aparecimento de outras doenças bucais, ao aumento de colesterol, a doenças cardíacas e distúrbios metabólicos, entre outros agravos (RODRIGUES et al., 2012)

Albuquerque et al. (2016), pesquisando a percepção de estudantes e educadores do Distrito Federal sobre práticas saudáveis de alimentação, constataram que os discentes souberam definir perfeitamente o que é uma alimentação saudável. Entretanto, estes relataram que preferem os alimentos não saudáveis, devido à aparência e sabor agradável.

De acordo com Moura et al. (2016), os alimentos mais consumidos pelos estudantes de 10 a 14 anos do Piaú amostrados em sua pesquisa foram carne (84\%) e carboidratos $(78,2 \%)$. Refrigerantes, frituras e biscoitos tiveram aceitação de $55 \%, 46 \%$ e $60,8 \%$ dos alunos, respectivamente; em última colocação ficaram os alimentos saudáveis $(31,8 \%)$. O índice de cárie destes escolares foi de $66,6 \%$, 
sendo encontrada associação significativa do tipo de alimentação e a presença de cárie.

Higiene Bucal

$\mathrm{Na}$ análise realizada não se identificou correlação estatística entre higiene bucal e cárie. Entretanto, 53,9\% dos estudantes que realizavam a limpeza oral possuíam dentes cariados (Tabela 2).

De acordo com Cipryano et al. (2011), a realização da limpeza bucal por crianças com auxílio e supervisão dos pais possui inúmeros benefícios, dentre eles a prevenção da doença cárie. A percentagem de cárie nos estudantes que escovavam os dentes sozinhos ficou em $53,9 \%$.

Para se atingir um nível de escovação adequado e independente é necessário que haja o reforço frequente no ensino de técnicas. Para crianças é recomendado o emprego de técnicas de escovação como a Stillman modificada (método do rolo) e a de Fones (circular), visando aumentar a autonomia e eficiência na escovação.

Castro (2006), ao avaliar a eficiência da escovação de crianças do ensino fundamental I de uma escola da região Amazônica, verificou que houve uma redução de 2,172 para 0,734 no índice de placa dos escolares após receberam informações sobre técnicas de higiene bucal.

O dentifrício fluoretado possui grande relevância em relação ao combate à cárie. Porém, deve ser utilizado com cuidado, pois a ingestão de flúor em demasia pode causar fluorose dentária e/ou contribuir para a osteoporose (COLUSSI et al., 2011).

Além disso, é importante que haja troca da escova dental a cada três meses. Após esse prazo as escovas se tornam menos eficientes na remoção da placa bacteriana de dentes e gengivas. Silva e Freitas (2011) realizaram pesquisa, com os responsáveis por escolares de 5 a 12 anos de uma escola pública da Paraíba, abordando o tempo de uso da escova de dentes. Nesse estudo, o esquecimento $(50 \%)$, a dificuldade financeira $(41 \%)$ e a falta de informação $(8,7 \%)$ foram os principais motivos alegados para a irregularidade da troca das escovas de dente pelos estudantes.

\section{Uso dos Serviços Odontológicos}

Não foram encontradas relações estatísticas no que diz respeito ao uso dos serviços odontológicos e a cárie. Entretanto, foi observado que $19,8 \%$ dos participantes com cárie ativa nunca visitaram o dentista, e 33\% o fizeram há mais de um ano (Tabela 2).

Cipryano et al. (2011) também observaram que grande porcentagem de escolares de 12 anos no estado de São Paulo nunca haviam frequentado o dentista (12\%).

A mesma percentagem (12\%) foi relatada por Muller et al. (2015) em estudantes de 05 a 12 anos de idade de escolas municipais do Rio Grande do Sul. O índice de experiência cárie desses escolares foi de 3,9 e 1,3 dentes aos 5 e aos 12 anos, respectivamente. 
Moura et al. (2016) ao realizar pesquisa com escolares de 10 a 14 anos na cidade de Picos, Piauí, relataram que apenas $21,7 \%$ dos entrevistados visitavam o dentista a cada seis meses.

Garcia et al. (2010) encontraram diferença no que diz respeito à frequência de visitas ao consultório odontológico, entre a escola pública e particular. Na escola particular $6,8 \%$ relataram ter visitado o dentista há mais de um ano enquanto que na pública essa porcentagem é de $23 \%$. O principal motivo alegado para a demora pela busca de atendimento odontológico do segundo grupo é acreditar que não há a necessidade de visitas periódicas ao dentista.

Amaral et al. (2013) e Freddo et al. (2008) verificaram melhor saúde bucal em escolares que possuíam maior renda e frequentavam o serviço odontológico privado.

\section{CONSIDERAÇÕES FINAIS}

Houve relação estatística significativa do fator demográfico cor/raça e socioeconômico escolaridade dos pais com a ocorrência de cárie dental nos escolares amostrados.

$$
\text { É importante o contínuo }
$$

aprimoramento da atenção básica em relação à saúde bucal da população por meio de informações midiáticas e/ou de campanhas realizadas pelo corpo administrativo municipal ou estadual.
A educação em saúde no ambiente escolar deve abranger, além dos discentes, o corpo docente e os pais/responsáveis dos escolares, visando à cooperação entre a escola e a família.

É necessário que a informação e o cuidado atinjam a população de forma simples, visando favorecer uma adesão homogênea. Portanto, ofertar atendimento odontológico de qualidade, junto com noções de alimentação e de hábitos saudáveis de higiene trarão saúde bucal e melhoras na qualidade de vida de toda a comunidade.

\section{REFERÊNCIAS}

ALBUQUERQUE, O. M. R. et al. Percepções de estudantes e educadores sobre alimentação adequada e saudável: diálogos com a promoção da saúde. Revista Eixo, Brasília, v. 5, n. 3, p.71-81, 2016. Disponível em: http://revistaeixo.ifb.edu.br/index.php/Revista Eixo/article/view/398/180. Acesso em: 17 nov. 2017.

ALMEIDA, A.L. et al. Experiência de cárie entre mães e filhos: influência de fatores socioeconômicos e comportamentais. Odontol. Clín.-cient., v. 10, n. 4, p.373-379, 2011. Disponível em: http://revodonto.bvsalud.org/pdf/occ/v10n4/a1 3v10n4.pdf. Acesso em: 25 set. 2017.

ALMEIDA, T. F. et al. Condições de saúde bucal em crianças, adolescentes e adultos cadastrados em unidades de Saúde da Família do Município de Salvador, Estado da Bahia, Brasil, em 2005. Epidemiol. Serv. Saúde, v. 21, n. 1, p.109-118, 2012. Disponível em: http://scielo.iec.pa.gov.br/pdf/ess/v21n1/v21n1 a11.pdf. Acesso em: 19 fev. 2017. 
AMARAL, R.C. et al. Cuidados odontológicos e fatores associados em escolares do município de IndaiatubaSP. Arquivos Odontológicos, Belo Horizonte, v. 49, n. 1, p.39-44, 2013. Disponível em: http://revodonto.bvsalud.org/scielo.php?pid=S 1516-09392013000100006\&script=sci_arttext. Acesso em: 30 out. 2017.

BAHIA. Secretaria de Infraestrutura hídrica e Saneamento. 2016. Disponível em: http://www.sihs.ba.gov.br/2016/11/264/Novosistemadeabastecimento-atende-zona-rural-deGovernador-

Mangabeira.htm. Acesso em: 30 out. 2017.

BÖNECKER, M. J. S.; FRAGA, C. P. T.; GUEDES-PINTO, A. C. Cárie Dentária. In: ISSÁO, M. GUEDES-PINTO, A. C. Manual de Odontopediatria. São Paulo: Santos, 2013. Cap. 6. p. 99-110.

BONOTTO, D. M. V. et al. Cárie dentária e gênero em adolescentes. Revista da Faculdade de Odontologia, v. 20, n. 2, p.202-207, 2015. Disponível em: http://seer.upf.br/index.php/rfo/article/view/49 53/3542. Acesso em: 19 fev. 2017.

BORGES, T. S.; BURGOS, M. S. Fatores associados à cárie: pesquisa de estudantes do sul do Brasil. Revista Paulista de Pediatria, v. 34, n. 4, p.489-494, 2016. Disponível em: http://www.scielo.br/pdf/rpp/v34n4/pt_01030582-rpp-34-04-0489.pdf. Acesso em: 19 fev. 2017.

BRASIL. Instituto Brasileiro de Geografia e Estatística. 2013. Disponível em: http://ibge.gov.br/cidadesat/painel/painel.php?1 ang $=\&$ codmun $=291160 \&$ search=bahia $\mid$ govern ador-mangabeira|infograficos:-dados-geraisdo-municipio. Acesso em: 11 mar. 2017.

BRASIL. Ministério da Educação. Instituto Nacional de Estudos e Pesquisas Educacionais - INEP. Censo Educacional 2015. Disponível em:

http://ibge.gov.br/cidadesat/painel/educacao.ph $\mathrm{p}$ ?lang $=\&$ codmun $=291160 \&$ search $=$ bahia|gove rnador-mangabeira|infograficos:-escolas- docentes-e-matriculas-por-nivel. Acesso em: 11 mar. 2017.

BRASIL. Ministério da Saúde. Diretrizes da Política Nacional de Saúde Bucal. Brasília, 2004.

BRASIL. Ministério da Saúde. Secretaria de Atenção a Saúde, Secretaria de Vigilância em Saúde, Departamento de Atenção Básica, coordenação geral de Saúde bucal. Projeto SB BRASIL 2010: Resultados principais. Brasília: Ministério da Saúde; 2011.

CARVALHO, F. S. Perfil Epidemiológico de Cárie Dentária em Pré-Escolares e o Conhecimento de Pais e de Educadores Sobre Saúde Bucal. 2009. 107 f. Dissertação (Mestrado) - Curso de Odontologia, Faculdade de Odontologia de Bauru da Cidade de São Paulo, Bauru, 2009. Disponível em: http://www.teses.usp.br/teses/disponiveis/25/2 5141/tde-14042009-151515/pt-br.php. Acesso em: 19 fev. 2017.

CASTILHO, A. R. F.et al. Influência do ambiente familiar sobre a saúde bucal de crianças: uma revisão sistemática. Jornal de Pediatria. V. 89, n. 2, p. 116-123. 2013. Disponível em: http://www.scielo.br/scielo.php?script=sci_artt ext\&pid=S0021-75572013000200003. Acesso em: 19 fev. 2017.

CASTRO, Roberta Francisca Martins de. Impacto imediato de ações educativas, preventivas e curativas sobre a saúde bucal de escolares de $1^{\mathrm{a}}$ a $4^{\mathrm{a}}$ série em um Município da Região Amazônica. 2006. 105 f. Dissertação (Mestrado) - Curso de Odontologia, Universidade de São Paulo, Bauru, 2006. Disponível em:

file://C:/Users/Helen/Downloads/RobertaCastr o.pdf. Acesso em: 16 abr. 2018.

COLUSSI, P.R.G. et al. Consumo de dentifrício e fatores associados em um grupo populacional brasileiro. Cadernos de Saúde Pública, v. 27, n. 3, p.546-554, 2011.

Disponível em: http://www.scielo.br/scielo.php?script=sci_artt 
ext\&pid=S0102-311X2011000300014. Acesso em: 18 set. 2017.

COSTA, M. F. et al. Aspectos preventivos da doença Cárie. In: PORTO, C. L. A.; PEREIRA, J. C.; NETTO, C. A. Cariologia: Grupo Brasileiro de Professores de Dentística. São Paulo: Artes Médicas, 2008. Cap. 3. p. 67-90.

CYPRIANO, S. et al.. Fatores associados à experiência de cárie em escolares de um município com baixa prevalência de cárie dentária. Ciência \& Saúde Coletiva, v. 16, n. 10, p.4095-4106, 2011. Disponível em: http://www.scielo.br/scielo.php?script=sci_artt ext\&pid=S1413-81232011001100015. Acesso em: 18 set. 2017.

ESKENAZI, E. M. S. et al. Avaliação da Experiência de Cárie e Qualidade de Vida Relacionada à Saúde Bucal de Escolares. Rev Bras Promoç Saúde, v. 28, n. 2, p. 198-205, 2015. Disponível em:

http://periodicos.unifor.br/RBPS/article/view/3 712/pdf. Acesso em: 26 mar. 2017.

FARGHALY, J.G. et al. Efeito do Gênero (Masculino e Feminino) sobre a Cárie Dentária e Parâmetros Salivares de Crianças. Pesq Bras Odontoped Clin Integr, v. 13, n. 1, p.11-15, 2013. Disponível em: http://revista.uepb.edu.br/index.php/pboci/artic le/view/1418/960. Acesso em: 25 set. 2017.

FIGUEIRA, T.R.; LEITE, I. C. G. Conhecimentos e Práticas de Pais Quanto à Saúde Bucal e suas Influências Sobre os Cuidados Dispensados aos Filhos. Pesq Bras Odontoped Clin Integr, v. 8, n. 1, p.87-92, 2008. Disponível em: https://www.arca.fiocruz.br/handle/icict/6689. Acesso em: 19 fev. 2017.

FREDDO, S. L. et al. Hábitos de higiene bucal e utilização de serviços odontológicos em escolares de uma cidade da Região Sul do Brasil. Cadernos de Saúde Pública., Rio de Janeiro, v. 24, n. 9, p.1991-2000, 2008. Disponível em: http://www.lume.ufrgs.br/handle/10183/49594. Acesso em: 30 out. 2017.
FREIRE, M. C. M. et al. Determinantes individuais e contextuais da cárie em crianças brasileiras de 12 anos em 2010. Revista de Saúde Pública, v. 47, n. 3, p.40-49. 2013. Disponível em: http://www.scielo.br/scielo.php?pid=S003489102013000900040\&script=sci_abstract. Acesso em: 19 fev. 2017.

FREITAS, S. F. T.; LACERDA, J. T.; NEUMANN, S. R. B. Severidade da Cárie Dentária e Fatores Associados em Escolares da Rede Pública de Joinville, Santa Catarina.

Pesq Bras Odontoped Clin Integr, n. 13, v. 4, p. 303-08, 2013. Disponível em: http://revista.uepb.edu.br/index.php/pboci/artic le/viewFile/1631/pdf_12. Acesso em: 26 mar. 2017.

FRIAS, A. C.; FRATUCCI, M. V. B. Os contornos sociais da cárie dentária. In: PORTO, C. L. A.; PEREIRA, J. C.; NETTO, C. A. Cariologia: Grupo Brasileiro de Professores de Dentística. São Paulo: Artes Médicas, 2008. Cap. 8. p. 211-225.

GARCIA, P. P. N. S. et al. Conhecimento Odontológico e Comportamento de Retorno de Escolares em Função do Tipo de Instituição (Pública ou Privada). Pesq Bras Odontoped Clin Integr, v. 10, n. 2, p.169-175, 2010. Disponível em:

http://revista.uepb.edu.br/index.php/pboci/artic le/viewFile/939/445. Acesso em: 26 mar. 2017.

GOMES, D.; ROS, M. A. A etiologia da cárie no estilo de pensamento da ciência odontológica. Ciência \& Saúde Coletiva, v. 13, n. 3, p.1081-1090, 2008. Disponível em: http://www.scielo.br/scielo.php?script=sci_artt ext\&pid=S1413-81232008000300031. Acesso em: 02 abr. 2017.

GOMES, S.S.M. et al. Cárie dentária em adolescentes da cidade de Recife- PE. RFO, v. 22, n. 1, p.62-68, 2017. Disponível em: http://docs.bvsalud.org/biblioref/2017/08/8487 20/artigo11.pdf. Acesso em: 18 set. 2017.

GUIOTOKU, S.K.; et al. Iniquidades raciais em saúde bucal no Brasil. Revista

Panamericana de Salud Pública, v. 31, n. 2, 
p.135-141, 2012. Disponível em:

http://www.scielosp.org/scielo.php?script=sci arttext\&pid=S1020-49892012000200007.

Acesso em: 18 set. 2017.

JEKEL, J. F.; ELMORE, J. G.; KATZ, D. L. Abordagens Epidemiológicas, Contribuições e Assuntos Correlatos. In: JEKEL, J. F.; ELMORE, J. G.; KATZ, D. L. Epidemiologia, Bioestatística e Medicina Preventiva. Porto Alegre: ArtMed, 2002. Cap. 1. p. 12-26.

LIMA, J. E. O. Cárie dentária: um novo conceito. Revista Dental Press de Ortodontia e Ortopedia Facial v. 12, n. 6, p.119-130, 2007. Disponível em:

http://www.scielo.br/scielo.php?script=sci_artt ext\&pid=S1415-54192007000600012. Acesso em: 22 mar. 2017.

MARCONI, M. A.; LAKATOS, E. M. Técnicas de Pesquisa. MARCONI, M. A.; LAKATOS, E. M. In: Fundamentos de Metodologia Científica. São Paulo: Atlas, S.A., 2010. Cap. 9. P. 157-197.

MOREIRA, T. P.; NATIONS, M. K.; ALVES, M. do S. C. F. Dentes da desigualdade: marcas bucais da experiência vivida na pobreza pela comunidade do Dendê, Fortaleza, Ceará, Brasil. Caderno Saúde Pública, Rio de Janeiro, v. 23, n. 6, p.1383-1392, 2007. Disponível em:

http://www.scielo.br/scielo.php?script=sci_artt ext\&pid $=$ S0102-311X2007000600013. Acesso em: 01 maio 2018.

MOURA, S. M. S. et al. Dieta e Cárie Dental em Escolares de 10 a 14 Anos na Cidade de Picos, Piauí. Journal Of The Health Sciences Institute. v.18, n. 1, p. 14-18, 2016.

Disponível em: http://www.pgsskroton.com.br/seer/index.php/ JHealthSci/article/view/3509. Acesso em: 19 fev. 2017.

MÜLLER, I. B. et al. Experiência de cárie e utilização do serviço público odontológico por escolares: estudo descritivo em Arroio do Padre, Rio Grande do Sul, 2013. Epidemiologia e Serviço de Saúde, v. 24, n. 3, p.759-770, 2015. Disponível em:
http://www.scielo.br/scielo.php?pid=S223796222015000400759\&script=sci abstract\&tln $\mathrm{g}=$ pt. Acesso em: 19 fev. 2017.

\section{NASCIMENTO, E. L. O sortilégio da} cor: Identidade, raça e gênero no Brasil. São Paulo: Selo Negro, 2003. 416 p. Disponível em: https://books.google.com.br/books?hl=ptBR\&lr; =\&id $=-$

ZAW 8 BhVcTQC\&oi=fnd\&pg=PA9\&dq=histó ria + da + cor/raça + no + brasil\&ots $=$ CVRL3iADIt \&sig=SJXfo48TsX6VjkEx14tSfwoJUZw\#v=o nepage \&q=história da cor/raça no brasil\&f=false. Acesso em: 15 nov. 2017.

PETROCELLI, J. L.; SABOIA, A.

\section{Características Étnicos-Raciais da}

População: Classificações e Identidades. Rio de Janeiro: Ibge, 2013. 208 p. Disponível em: https://biblioteca.ibge.gov.br/visualizacao/livro s/liv63405.pdf. Acesso em: 15 nov. 2017.

PORTO, C. L. A.; PEREIRA, J. C.; NETTO, C. A. Cariologia: Grupo Brasileiro de Professores de Dentística. São Paulo: Artes Médicas, 2008.

RAMOS, J.S. Ciência e racismo: uma leitura crítica em raça e assimilação em Oliveira Viana. Hist., Cienc., Saúde - Manguinhos, v.10, n.2, p.573-601, 2003. Disponível em: http://www.scielo.br/scielo.php?pid=S0104$59702003000200005 \&$ script $=$ sci_abstract\&tln $\mathrm{g}=\mathrm{pt}$ Acesso em: 20 mar. 2017.

RODRIGUES, J.A. et al. Cárie Dental: Conceitos e teorias. In: PORTO, C. L. A.; PEREIRA, J. C,; NETTO, C. A. Cariologia: Grupo Brasileiro de Professores de Dentística. São Paulo: Artes Médicas, 2008. Cap. 1. p. 114.

RODRIGUES, P.R. et al. Fatores associados a padrões alimentares em adolescentes: um estudo de base escolar em Cuiabá, Mato Grosso. Revista Brasileira de Epidemiologia, Jhhg, v. 15, n. 3, p.662-674, 2012. Disponível em: http://www.scielo.br/scielo.php?script=sci artt ext\&pid=S1415-790X2012000300019. Acesso em: 18 set. 2017. 
SANTOS, G. M. et al. Contexto Familiar e Condições de Saúde Bucal em Crianças de 2 A 5 anos no Município de Salvador, Bahia: Uma Análise Descritiva. Revista Baiana

de Saúde Pública, v.35, n.2, p.277-288, 2011. Disponível em:

http://inseer.ibict.br/rbsp/index.php/rbsp/article /viewFile/303/272. Acesso em: 26 mar. 2017.

SANTOS, L.B.L. et al. Fatores Associados à Presença e Severidade da Cárie em Escolares do Ensino Fundamental de Governador Mangabeira, Bahia. Textura, v. 10, n. 18, p.43-53, 2017. Disponível em: http://dx.doi.org/10.22479/244799342017v10n 18p42-52. Acesso em: 19 set. 2017.

SEGRE, M.; FERRAZ, F. C. O conceito de saúde. Revista de Saúde Pública, v. 31, n. 5, p.538-542, 1997. Disponível em: http://www.scielo.br/pdf/rsp/v31n5/2334.pdf. Acesso em: 18 mar. 2017.

SILVA, P. F.; FREITAS, C. H. S. de $M$. Análise de motivos que dificultam a adoção de hábitos de higiene bucal saudáveis com relação à cárie dentária: avaliação de uma escola pública da

Paraíba. Arq. Odontol. [online]. 2011, vol.47, n.1, pp. 38-44. ISSN 1516-0939. Disponível em:

http://revodonto.bvsalud.org/pdf/aodo/v47n1/a 06v47n1.pdf. Acesso em: 16 abr. 2018.

SILVA, D.C.A. et al. Percepção de adolescentes sobre a prática de alimentação saudável. Ciência \& Saúde Coletiva, v. 20, n. 11, p.3299-3308, 2015. Disponível em: http://www.scielosp.org/scielo.php?script=sci arttext\&pid=S1413-81232015001103299.

Acesso em: 08 ago. 2017.

SILVEIRA, M.F. et al. Cárie dentária e fatores associados entre adolescentes no norte do estado de Minas Gerais, Brasil: uma análise hierarquizada. Ciência \& Saúde Coletiva, v. 20, n. 11, p.3351-3364, 2015. Disponível em: http://www.scielo.br/scielo.php?pid=S1413$81232015001103351 \&$ script $=$ sci_abstract $\&$ th $\mathrm{g}=$ pt. Acesso em: 18 set. 2017.
SOUZA, M. E. et al. Relação entre fatores socioeconômicos, clínicos e saúde bucal em escolares da zona rural: um estudo longitudinal. Revista da Faculdade de Odontologia, v. 20, n. 2, p.208-215, 2015. Disponível em: http://seer.upf.br/index.php/rfo/article/view/50 18. Acesso em: 19 fev. 2017.

Hellen Catarinne Pereira dos Santos de Santana Odontóloga pela Faculdade Maria Milza - FAMAM

Fernando Francisco Chagas dos Santos

Odontóloga pela Faculdade Maria Milza - FAMAM

Ana Conceição de Oliveira Cravo Teixeira Bacharel em Odontologia (UEFS).

Mestre em Desenvolvimento Regional e Meio Ambiente Docente da FAMAM

Larissa Rolim Borges-Paluch

Doutora em Ciências Biológicas - UFPR. Docente do Mestrado em Desenvolvimento Regional e Meio Ambiente da FAMAM 